\title{
The terminal ballistic experimental analysis of an empty and full water tank
}

\author{
M. R. Aziz, W. Kuntjoro \& N. V. David \\ Faculty of Mechanical Engineering, UiTM, Malaysia
}

\begin{abstract}
This paper presents the footage from a hi-speed camera used in the experiment on both cases of a non-filled and water-filled aluminium tank. The objective was to determine the failure stages that will be used as a reference in the simulation works later on. The tank was impacted by fragment simulating projectiles (FSP) at $260 \mathrm{~m} / \mathrm{s}$ for the non-filled tank and $972 \mathrm{~m} / \mathrm{s}$ for the water-filled tank. The aluminium tank was $3 \mathrm{~mm}$ thick, $150 \mathrm{~mm}$ wide and $750 \mathrm{~mm}$ long. The ends of the tank were closed with two Polymethyl methacrylate (PMMA) windows. The gas gun was used to launch the projectile and a digital chronograph was used to capture the velocity of the FSP that impacted the tank. For recording purposes, a digital high speed camera with the capability of 250,000 frames per second (max) and the highest resolution of $1024 \times 1024$ was used. For the data acquisition and processing, Photron Fastcam Viewer (PFV) software was used. The test was conducted at the Science and Technology Research Institute for Defence (STRIDE), Batu Arang, Selangor, Malaysia. The results showed four main failure stages for the non-filled tank, these being, first contact between FSP and the tank, partial perforation, full perforation with FSP and plug still intact and lastly separation of FSP and plug. Meanwhile for the water-filled tank, there were seven main failure stages, which were first contact between FSP and the tank, partial perforation, full perforation, drag phase, cavity phase, bounce wave event and the collapse of the cavity.

Keywords: fragment simulating projectile, high speed camera, tensile test, terminal ballistic.
\end{abstract}




\section{Introduction}

Giglio and Manes [7] defined terminal ballistics as one of the domains in the ballistic that involves the behaviour of the impactor or projectile and its effect towards the target such as a shape of damage and also residual stress. Hetherington [8] has conducted a comprehensive study to investigate the energy and momentum changes during the ballistic perforation. There are numerous studies in predicting the ballistic limit (BL). Jenq et al. [9] carried out a study to predict the BL of the plain woven glass/epoxy composite. Grujicic et al. [10] proposed a simple method to determine the BL for soda-lime glass. Sevkat [11] conducted an experiment and numerical method to estimate BL for woven composite beams. Aziz et al. [25] conducted the simulation of a wall collision by using the Smoothed Particle Hydrodynamics (SPH) method. Chi et al. [12] investigated $\mathrm{BL}$ for bi-layer alumina/alumina armour by using the semi analytical method.

Researchers have contributed a lot of technical papers in analysing factors that affect BL. Borvik et al. [13] studied the behaviour of Weldox $460 \mathrm{E}$ steel plates impacted by blunt-nosed cylindrical projectiles in the lower ordnance velocity regime. Seyed Yaghoubi and Liaw [14] analysed the effect of thickness towards the ballistic impact behaviours of GLARE 5 fibre-metal laminated beams. Li et al. [15] carried out an experiment on Optimal Transportation Mesh free (OTM), particularly on contact and fracture in BL. Ben-Dor et al. (2013) investigated the effect of the layers of metal shields against a sharp-nosed projectile [16]. Seyed Yaghoubi and Liaw [17] conducted a BL experiment for GLARE 5 FML beams when the lay-up orientation is varied. Wielewski et al. [18] studied BL for spaced multi-layer plate structures. Aziz et al. [19] analysed the ballistic limit for an aluminium tank impacted by fragment simulating projectile (FSP). Varas et al. [20] stated that Hydrodynamic Ram (HRAM) involves a high-speed projectiles perforated tank, which is filled with certain fluid, and transfers kinetic energy to the surrounding walls. Then, Varas et al. [21] studied the HRAM phenomenon with a projectile impacted water-filled aluminium tank. Disimile et al. [22] carried out an experiment for the three different materials of spherical projectiles i.e. tungsten, steel and aluminium. In another year, Disimile et al. [23] investigated the mitigation of shock waves by introducing mitigation members in the tank. Deletombe et al. [24] studied the HRAM phenomenon by using $7.62 \mathrm{~mm}$ bullet as the impactor.

From the literature reviews discussed here, the majority concentrates on the ballistic limit and a few discuss the terminal ballistic of a liquid-filled tank and a non-filled tank. Therefore, this paper intends to fill this gap by reporting the ballistic terminal study of a non-filled and water-filled aluminium tank.

\section{Methodology}

In this study, a tensile test and ballistic test were conducted according to the Standard Test Methods for Tension Testing of Metallic Materials [1] and the Department of Defence Test Method Standard: V50 Ballistic Test for Armour 
[2], respectively. Since the aluminium used was received from the manufacturer it was therefore important to determine the yield strength and Young's modulus of the tank. So, a tensile test needed to be conducted. The aluminium tank that was used was $3 \mathrm{~mm}$ thick, $150 \mathrm{~mm}$ wide and $750 \mathrm{~mm}$ long. Figure 1 shows the tensile test specimen. Table 1 shows the details of dimensions in $\mathrm{mm}$. Five specimens were fabricated, using a wire cutting machine.

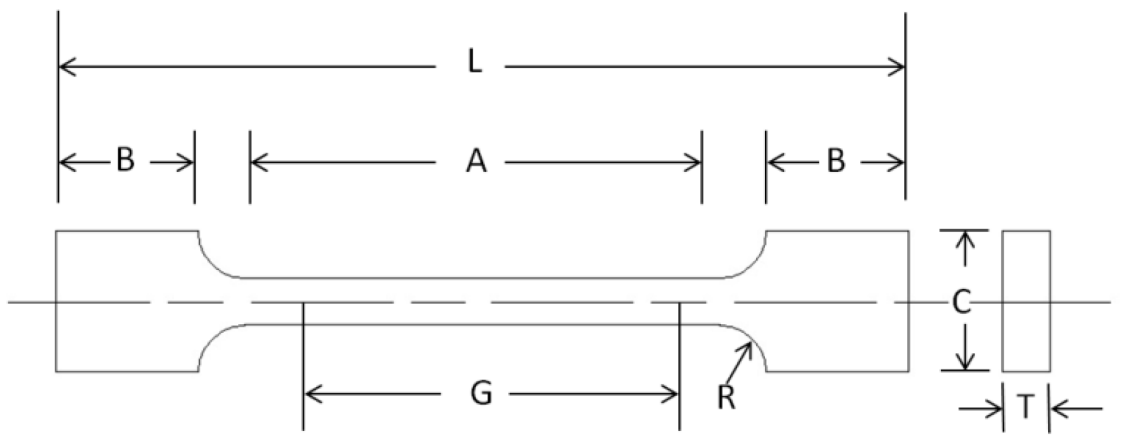

Figure 1: Tensile test specimen.

Table 1: Details of tensile test specimen.

\begin{tabular}{|l|c|}
\hline G: gage length & $25.0 \pm 0.2$ \\
\hline W: width & $6.0 \pm 0.1$ \\
\hline T: thickness & 3 \\
\hline R: radius of fillet & 6 \\
\hline L: overall length & 100 \\
\hline A: length of reduced section & 32 \\
\hline B: length of grip section & 30 \\
\hline C: width of grip section & 10 \\
\hline
\end{tabular}

For the tensile test, the cross-head speed was set to $2 \mathrm{~mm} / \mathrm{min}, 5 \mathrm{~mm} / \mathrm{min}$, $8 \mathrm{~mm} / \mathrm{min}, 10 \mathrm{~mm} / \mathrm{min}$ and $12 \mathrm{~mm} / \mathrm{min}$. This step was taken to ensure that the yield strength obtained was accurate. A Universal Testing Machine Shimadzu $50 \mathrm{kN}$ was employed for this test. The data obtained from the test was processed using Trapezium II software. The ends of the tank were closed with two Polymethyl methacrylate (PMMA) windows, which fixed to the tank with four steel bars. Figure 2 shows the actual and schematic diagram of the aluminium tank used in the study. The contact between the tank and the PMMA window was sealed with silicone. The tank was impacted by a fragment simulating projectile (FSP). They were cylindrical with a blunt chisel-shaped nose and a raised flange at the base. These FSP was fixed into the $7.62 \mathrm{~mm}$ bullet's jacket with a sabot. Figure 3 shows the completed projectile, the sabot and FSP used in the test. In order to vary the velocity of the projectile, different charge weights were applied to the bullet's jacket. 

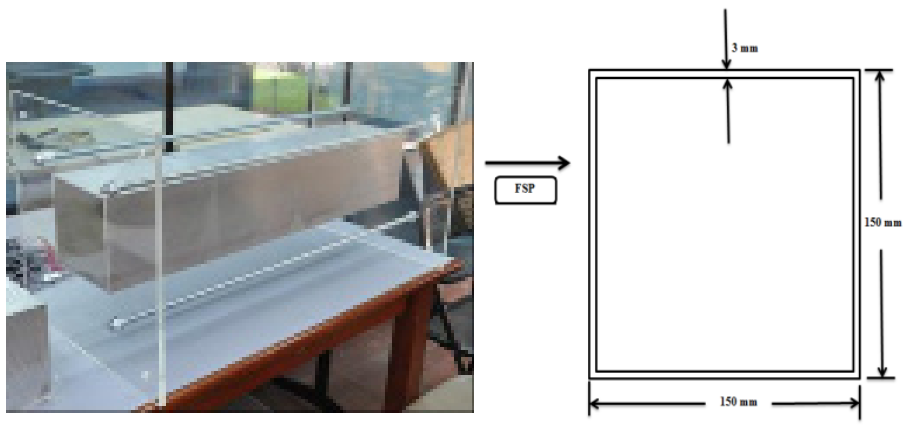

Figure 2: Aluminium tank.

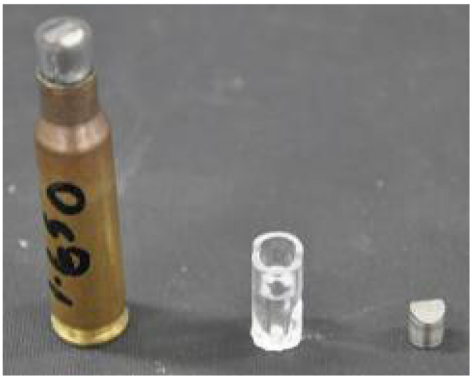

Figure 3: Completed projectile (left), sabot (middle) and FSP (right).

Before the ballistic test took place several rounds of shots using $7.62 \mathrm{~mm}$ live bullets were conducted. The purpose was to see whether the chronograph was able to capture the correct velocity and if the high speed camera was able to capture the required frame. Once these two instruments were in good condition, the real test was conducted. Figures 4 and 5 show the set-up of the ballistic test (lateral view) and the actual set-up picture, respectively. For recording purposes, a Photron FASTCAM APX RS digital high-speed camera with a Nikon lens was used. The camera has the capability of 250,000 frames per second (max) with the highest resolution of $1024 \times 1024$. For the data acquisition and processing, Photron FASTCAM Viewer (PFV) software was used. One Hydrargyrum medium-arc iodide (HMI) lamp with a 1200 Watt bulb was used to provide sufficient light during the test. The gas gun was used to launch the projectile and a ProChrono Digital Chronograph was used to capture the velocity of FSP that impacted the tank.

The Department of Defence Test Method Standard $-V_{50}$ Ballistic Test for Armour - details the requirements of conducting a ballistic test, also known as V50 [2]. For a $7.62 \mathrm{~mm}$ calibre, the velocity should remain approximately $780 \mathrm{~m} / \mathrm{s}$ after travelling for $100 \mathrm{~m}$. The chronograph must be able to measure to at least the nearest microsecond (10e-6s). The charge (propellant), which is either standard or suitable for the weapon, was employed and kept in storage at 
$19^{\circ}-24^{\circ} \mathrm{C}$ with $50 \pm 5 \%$ humidity. The test should be performed in a standard atmosphere of $23 \pm 2^{\circ} \mathrm{C}$. The warm-up test is important to ensure the target alignment and for the establishment of the specific striking velocity. Therefore, during the warm-up test, the target should be impacted exactly as targeted. Additional rounds need to be done to achieve proper alignment and stable striking velocity. In this study, all these requirements were met before the actual test.

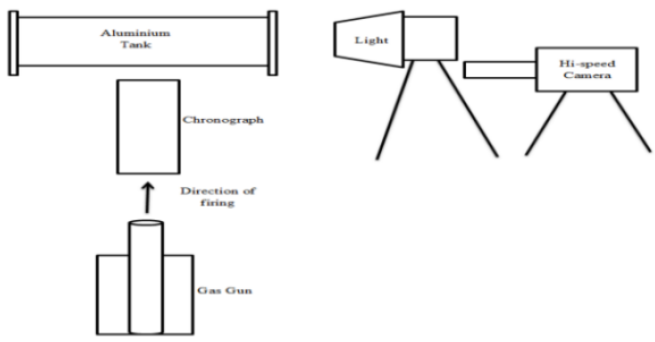

Figure 4: Set-up of ballistic test.

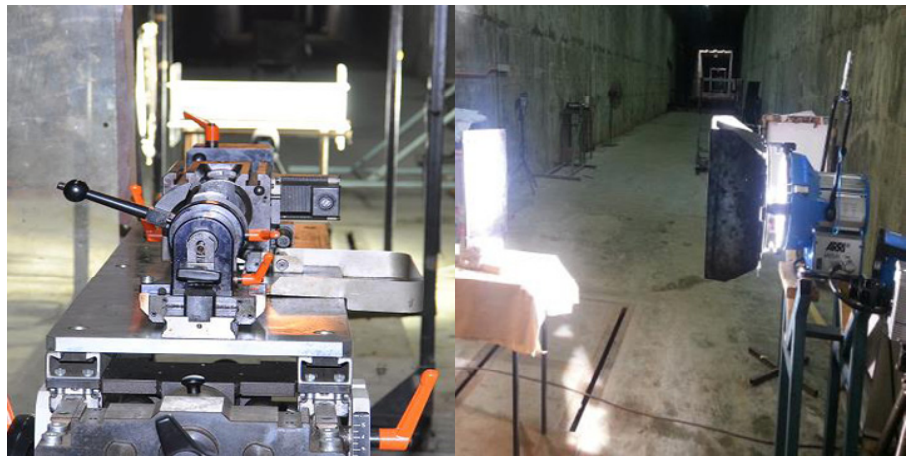

Figure 5: Actual picture of the set-up.

\section{Results and discussion}

\subsection{Tensile test}

Figure 6 shows a stress-strain diagram for all the tensile tests. Table 2 summarizes the value of the ultimate stress and Young's modulus, $E$, obtained from the experiment. In order to determine the value of $E, 0.2 \%$, the offset yield method was employed (Riley et al. [3]). By taking an average of the value of ultimate strength and Young's modulus it was found that the ultimate strength was equal to 260.2 MPa and the Young's modulus was equal to $72.6 \mathrm{GPa}$. Both these values are quite similar to the Aluminium material, cast 195-T6 (Riley et al. [4]). T6 means that it has been heat-treated and artificially aged 
(Brady et al. [5]). Fragment simulating projectile (FSP) was made from cold rolled and annealed steel conforming to composition 4340H (MIL-P-46593A, ORD, 1962 [6]). The ultimate strength of FSP is $745 \mathrm{MPa}$, the yield strength is $475 \mathrm{MPa}$, the Young's modulus, E, is $205 \mathrm{GPa}$ and the Poisson's ratio is 0.29 (www.matweb.com [26]).

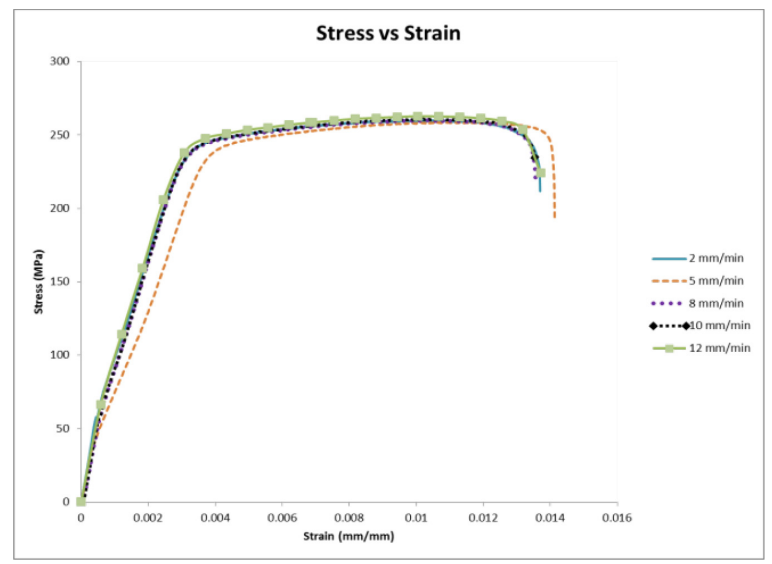

Figure 6: Stress-strain curves.

Table 2: Ultimate strength and Young's modulus.

\begin{tabular}{|c|c|c|}
\hline $\begin{array}{c}\text { Cross-head speed } \\
(\mathrm{mm} / \mathrm{min})\end{array}$ & $\begin{array}{c}\text { Ultimate strength } \\
(\mathrm{MPa})\end{array}$ & $\begin{array}{c}\text { Young's modulus } \\
(\mathrm{GPa})\end{array}$ \\
\hline 2 & 260 & 73 \\
\hline 5 & 259 & 69 \\
\hline 8 & 260 & 73 \\
\hline 10 & 261 & 74 \\
\hline 12 & 261 & 74 \\
\hline
\end{tabular}

\subsection{Terminal ballistic for non-filled tank}

For this study, the velocity of the FSP was set to $260 \mathrm{~m} / \mathrm{s}$. The ballistic limit conducted showed that the ballistic limit for the first wall of the tank was equal to $257.7 \mathrm{~m} / \mathrm{s}$, as obtained by Aziz et al. [19]. Figure 8 shows the footage from the high-speed camera during the terminal ballistic event. In this case, the high-speed camera was set to 50,000 frames per second with a resolution of $256 \times 128$ and the shutter was set to $1 / 60000$ second. Figure 8(a) shows the first contact between the FSP and the wall of the tank, which produced some sparks, due to friction between them. The time was considered equal to 0 second at this stage. During this event, the wall of the tank experienced bulging as shown in Figure 9. The footage in Figure 8(b), which occurred at $20 \mu \mathrm{s}$ after first impact, 
shows the plug that was created. It was also shown that the FSP partially perforated the wall of the tank. The wall of the tank experienced piercing and perforation during this stage (Figure 10).

In Figure 7(c), the FSP had perforated the tank and caused the plug to push out from the wall of the tank, however they were still intact. At the same time, the wall of the tank had been deformed due to petalling. The velocity after the perforation was almost constant due to negligible sliding friction between FSP and the plug, as stated by Borvik et al. [13]. When the time was equal to $140 \mu \mathrm{s}$, FSP and the plug had just separated from each other, as shown in Figure 7(d). Borvik et al. [13] also suggested that the unsymmetrical petalling caused the plug to rotate and it was believed that the plug achieved a rapid increase in velocity before it stabilized at a velocity 15\% higher than the FSP. Figures 10 and 11 show the petalling of the tank and the plugs created from the event, respectively. In general, Aziz et al. [25] obtained about the same result from their simulation.

Li et al. [15] found in their study that the whole process of perforation involved large unconstrained plastic flows, contact and friction, fracture and fragmentation and complex material behaviour. The failure of the target plate was affected by two factors, these being, the ductile flow of the target material and brittle shear failure around the plug, which were carried forward by the FSP. Hetherington [8] observed that if the impact velocities are increased, the amount of brittle failure will increase, which leads to more debris from the target.

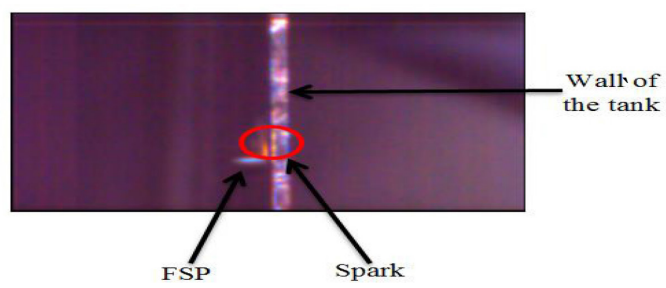

(a)

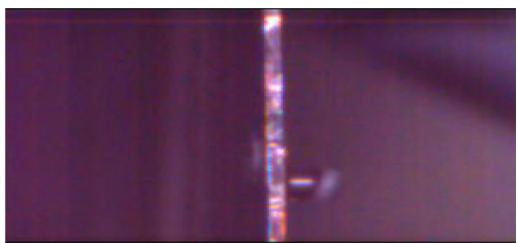

(c)

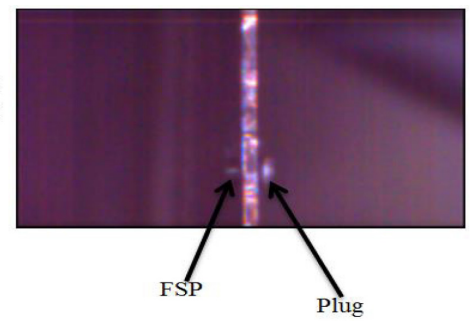

(b)

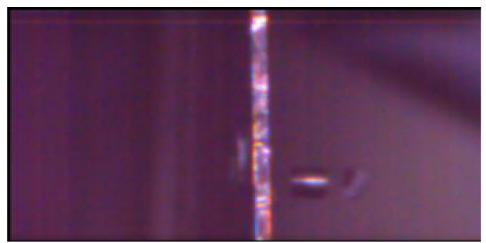

(d)

Figure 7: Footage of terminal ballistic for non-filled tank. 


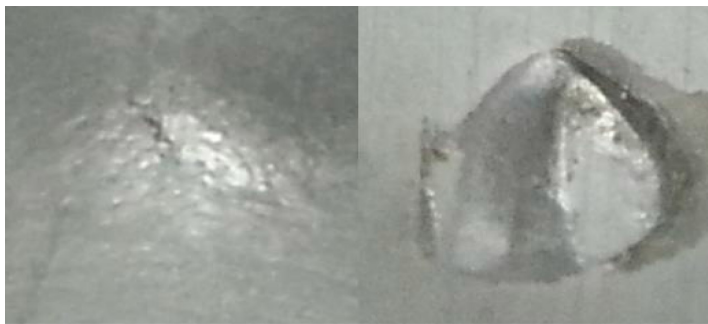

$\begin{array}{ll}\text { (a) Front view } & \text { (b) Rear view }\end{array}$

Figure 8: Bulging deformation.

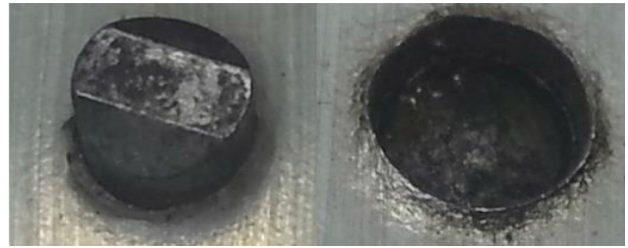
(a) Front view
(b) Rear view

Figure 9: Piercing and partial perforation deformation.

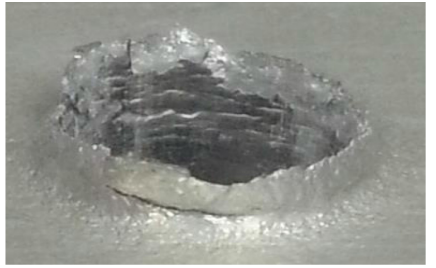

Figure 10: Petalling deformation.

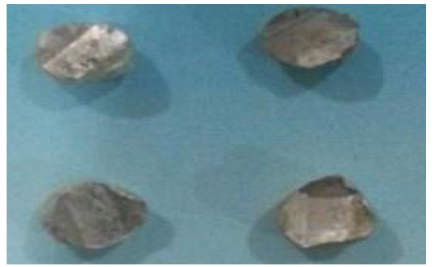

Figure 11: Plugs created from the wall of the tank. 


\subsection{Terminal ballistic for water-filled tank}

For this test, the velocity of FSP was set to the maximum, which was $972 \mathrm{~m} / \mathrm{s}$. This was the maximum FSP that can achieved by using the maximum charge weight. From the test conducted, the ballistic limit for the second wall of the non-filled tank was $481 \mathrm{~m} / \mathrm{s}$ (Aziz et al. [19]). So, when it came to the waterfilled tank, the velocity was increased to determine the ballistic limit. But, the FSP still failed to perforate the second wall even at the highest speed, i.e. $972 \mathrm{~m} / \mathrm{s}$, which was employed. The second wall had bulging deformation only (as it is shown in Figure 8). The setting for the high-speed camera was the same as for the non-filled tank, except for the shutter, which was set to $1 / 55000$ second to get better footage. Several pieces of the recorded footage are shown in Figure 12. Generally, it shows how the FSP perforated the wall of the tank, followed by the penetration of the fluid, creating a cavity and then travelling through the fluid. In the full video recorded, several collapsed and expansions of the cavity were produced during several microseconds.

In the Figure 12 (a), water was disturbed a little bit because the FSP first had contact with the first wall of the tank and the time was considered equal to $0 \mathrm{~s}$. Followed by Figure 12 (b), FSP perforated the first wall of the tank partially at a time equal to $40 \mu \mathrm{s}$. Figure 12 (c) shows that the FSP had successfully perforated the first wall of the tank. The time was equal to $120 \mu$ s. This event was known as the shock phase, as the impact energy was transferred to the fluid and generated a high-pressure hemispherical shock wave (Varas et al. [20]), which propagated through the fluid (Disimile et al. [22]). In Figure 12 (d), the drag phase occurred at the time equal to $200 \mu \mathrm{s}$. In this particular event, some of the kinetic energy from the FSP was changed to fluid motion and the displacement of the fluid from the path generated by FSP created a radial pressure and a cavity behind it (Disimile et al. [23]). It was observed that the first wall started to deflect and caused reflection. At the time equal to $320 \mu \mathrm{s}$, the cavitation phase occurred as shown in Figure 12 (e). It clearly shows that the size of the cavity was getting bigger. At this stage, the cavity was created due to a reduced field around the FSP (Disimile et al. [23]). The bounce wave occurred, as shown in Figure 12 (f), at a time equal to $600 \mu \mathrm{s}$. This was due to the fact that FSP failed to perforate the second wall of the tank. Thus, the FSP bounced along with the wave. In Figure $12(\mathrm{~g})$, the cavity seems to be approximately its largest size, whereby it spans the entire tank, also known as the collapse of the cavitation. At the end of the test, some bubbles appeared closed to the free space between the water and the tank. This occurred when the time was equal to $1040 \mu \mathrm{s}$.

In this test, the fluid that transformed into vapour and then changed back to fluid was considered as negligible. Therefore, for the incompressible fluid such as the water in this study, the conservation of mass and volume of the fluid implied that the fluid expansion was equal to the gas bubble created (Deletombe et al. [24]). 


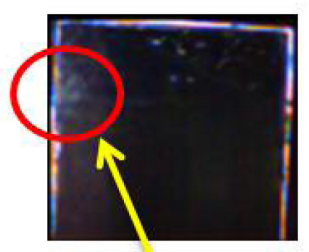

Water was disturbed FSP partially perforated the first wall

(a)

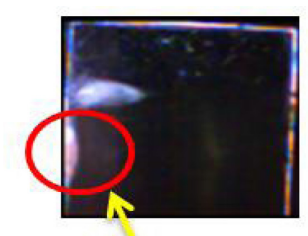

The first wall started to deflect

(d)

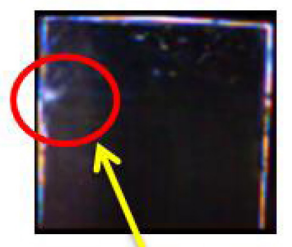

(b)

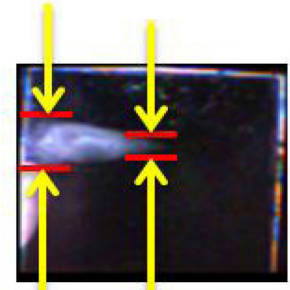

Cavitation getting bigger

(e)

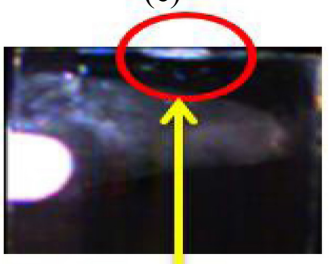

Bubbles

(g)

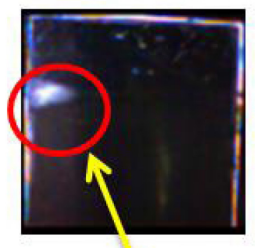

FSP successfully perforated the first wall

(c)

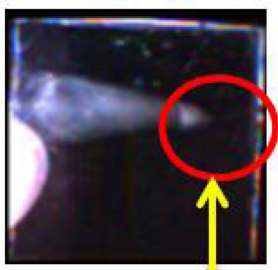

Bounce wave

(f)

Figure 12: Footage of terminal ballistic for water-filled tank.

\section{Conclusion}

In this study, the following conclusions were achieved:

i. The tensile test conducted was successfully able to determine the type of material for the tank, which was cast Aluminium 195-T6. All five tensile tests showed similar results due to homogenous material even though different the cross-head speed was set.

ii. For the non-filled tank, four main stages were observed: 1) first contact which created some spark, 2) FSP partially perforated the wall and created the plug in the process, 3) FSP successfully perforated the wall and the plug was still intact with the FSP, 4) FSP moved away from the wall, as did the plug. At this moment, they were separated. 
iii. For the water-filled tank, seven main stages developed: 1) the first contact between the FSP and the wall, which caused the water in the tank to become stirred, 2) there was partial perforation of the wall by the FSP, 3) this was followed by the shock phase when the whole FSP perforated the wall, 4) the drag phase - the displacement of the FSP caused a cavity behind it, 5) the cavity phase, whereby the cavitation inside the fluid was getting bigger and bigger, 6) the bounce wave phase, due to the FSP, failed to perforate the second wall of the tank, 7) lastly, the collapse of the cavitation occurred.

\section{Acknowledgements}

The authors would like to thank the Ministry of Science, Technology and Innovation (MOSTI) Malaysia for the financial support through e-Science Fund 06-01-01-SF0509, Research Management Institute (RMI) UiTM and the Ministry of Education (MOE) Malaysia.

\section{References}

[1] Standard Test Methods for Tension Testing of Metallic Materials, Designation: E8/E8M-11, pp. 3, ASTM International.

[2] Department of Defence Test Method Standard, V50 Ballistic Test for Armour, pp. 8-9, MIL-STD-662f (18 December 1997), MIL-STD-662E (22 January 1987).

[3] William F. Riley, Leroy D. Sturges \& Don H. Morris, Mechanics of Materials, 6th. Edition, John Wiley \& Sons, Inc., pp. 154, 2007.

[4] William F. Riley, Leroy D. Sturges \& Don H. Morris, Mechanics of Materials, 6th. Edition, John Wiley \& Sons, Inc., table in the appendix, 2007.

[5] George S. Brady, Henry R. Clauser \& John A. Vaccari, Materials Handbook, 15th edition, McGraw-Hill, page 51, 2002.

[6] MIL-P-46593A, ORD, Projectile, Calibres .22, .30, .50 and $20 \mathrm{~mm}$ fragment \& simulating (Superseding MIL-P-46593) (s/s by MIL-DTL46593B), Military Specifications and Standards, standard published 10/12/1962.

[7] M. Giglio \& A. Manes, Terminal Ballistic Effect on the Crack Growth Assessment of a Helicopter Rotor Drive, Engineering Fracture Mechanics, vol. 78, pp. 1542-1554, 2011.

[8] J. G. Hetherington, Energy and Momentum Changes During Ballistic Perforation, Int. J. Impact Eng., Vol. 18, No. 3, pp. 319-337, 1996.

[9] S. T. Jenq, H.S. Jing \& C. Chung, Predicting the Ballistic Limit for Plain Woven Glass/Epoxy Composite Laminate, Int. J. Impact Eng., Vol. 15, No. 4, pp. 451-464, 1994.

[10] M. Grujicic, B. Pandurangan, N. Coutris, B.A. Cheeseman, C. Fountzoulas, P. Patel, D.W. Templeton \& K.D. Bishnoi, A Simple 
Ballistic Material Model for Soda-lime Glass, International Journal of Impact Engineering, Vol. 36, pp. 386-401, 2009.

[11] Ercan Sevkat, Experimental and Numerical Approaches for Estimating Ballistic Limit Velocities of Woven Composite Beams, International Journal of Impact Engineering, Vol. 45, pp. 16-27, 2012.

[12] Runqiang Chi, Ahmad Serjouei, Idapalapati Sridhar \& Geoffrey E.B. Tan, Ballistic Impact on Bi-layer Alumina/Aluminium Armour: A Semianalytical Approach, International Journal of Impact Engineering, Vol. 52, pp. 37-46, 2013.

[13] T. Borvik, M. Langseth, O.S. Hopperstad \& K.A. Malo, Ballistic Penetration of Steel Plates, International Journal of Impact Engineering, Vol. 22, pp. 855-886, 1999.

[14] A. Seyed Yaghoubi \& B. Liaw, Thickness Influence on Ballistic Impact Behaviours of GLARE 5 Fibre-metal Laminated Beams: Experimental and Numerical studies, Composite Structures, Vol. 94, pp. 2585-2598, 2012.

[15] B. Li, A. Kidane, G. Ravichandran \& M. Ortiz, Verification and Validation of the Optimal Transportation Mesh free (OTM) Simulation of Terminal Ballistics, International Journal of Impact Engineering, Vol. 42, pp. 25-36, 2012.

[16] G. Ben-Dor, A. Dubinsky \& T. Elperin, About Effect of Layering on Ballistic Properties of Metal Shields Against Sharp-nosed Rigid Projectiles, Engineering Fracture Mechanics, Vol. 102, pp. 358-361, 2013.

[17] A. Seyed Yaghoubi \& B. Liaw, Effect of Lay-up Orientation on Ballistic Impact Behaviours of GLARE 5 FML Beams, International Journal of Impact Engineering, Vol. 54, pp. 138-148, 2013.

[18] Euan Wielewski, Alan Birkbeck \& Ron Thomson, Ballistic Resistance of Spaced Multi-layer Plate Structures: Experiments on Fibre Reinforced Plastic Targets and an Analytical Framework for Calculating the Ballistic Limit, Materials and Design, Vol. 50, pp. 737-741, 2013.

[19] M. R. Aziz, W. Kuntjoro, N. V. David \& F. Rais, An Experimental Study on the Ballistic Impact Behaviour of Non-filled Tank against Fragment Simulating Projectile (FSP), periodical Applied Mechanics and Materials with the title Advances in Manufacturing and Mechanical Engineering, Vol. 393, pp. 409-414, 2013.

[20] D. Varas, R. Zaera \& J. Lopez-Puente, Numerical Modelling of the Hydrodynamic Ram Phenomenon, International Journal of Impact Engineering, Vol. 36, pp. 363-374, 2009.

[21] D. Varas, R. Zaera \& J. Lopez-Puente, Experimental Analysis of Fluidfilled Aluminium Tubes Subjected to High-velocity Impact, International Journal of Impact Engineering, Vol. 36, pp. 81-91, 2009.

[22] Peter J. Disimile, Luke A. Swanson \& Norman Toy, The Hydrodynamic Ram Pressure Generated by Spherical Projectiles, International Journal of Impact Engineering, Vol. 36, pp. 821-829, 2009.

[23] Peter J. Disimile, John Davis \& Norman Toy, Mitigation of Shock Waves within a Liquid Filled Tank, International Journal of Impact Engineering, Vol. 38, pp. 61-72, 2011. 
[24] E. Deletombe, J. Fabis, J. Dupas \& J.M. Mortier, Experimental Analysis of $7.62 \mathrm{~mm}$ Hydrodynamic Ram in Containers, Journal of Fluids and Structures, Vol. 37, pp. 1-21, 2013.

[25] M.R. Aziz, W. Kuntjoro \& N.V. David, Simulation of projectile-wall collision by using smoothed particle hydrodynamics (SPH), Proc. of IEEE Int. Conf. on Control System, Computing and Engineering, pp. 222-226, 2012.

[26] MatWeb, Your Source for Materials Information. www.matweb.com 